\title{
Teacher Learning within a Multinational Project in an Upper Secondary School
}

\author{
Liisa Ilomäki, ${ }^{1}$ Minna Lakkala, ${ }^{1}$ Auli Toom, ${ }^{2}$ and Hanni Muukkonen ${ }^{1,3}$ \\ ${ }^{1}$ Faculty of Educational Sciences, University of Helsinki, Helsinki, Finland \\ ${ }^{2}$ Centre for University Teaching and Learning, Faculty of Educational Sciences, University of Helsinki, Helsinki, Finland \\ ${ }^{3}$ Faculty of Education, University of Oulu, Oulu, Finland \\ Correspondence should be addressed to Liisa Ilomäki; liisa.ilomaki@helsinki.fi
}

Received 10 March 2017; Revised 14 May 2017; Accepted 11 June 2017; Published 18 July 2017

Academic Editor: Eduardo Montero

Copyright (C) 2017 Liisa Ilomäki et al. This is an open access article distributed under the Creative Commons Attribution License, which permits unrestricted use, distribution, and reproduction in any medium, provided the original work is properly cited.

\begin{abstract}
In this case study, we investigated teachers' professional learning within a multinational project in an upper secondary school. The aim of the study was to investigate how the participating teachers adopted and applied the trialogical approach (TLA) in their pedagogical practices and their challenges in doing that. The mixed method approach was used for data collection and analysis. About one-fourth of the teachers participated in the activities, ten females and three males. Three groups were identified, based on their activity in the project: pilot teachers, active adopters, and adopters. Altogether 79 students (38 males and 41 females) answered a questionnaire concerning the pedagogical practices. The pedagogical revisions were well in line with TLA; the revised courses as well as new iterations and new ideas were indicators of the teachers' creative implementation processes. However, some of the TLA ideas were more difficult to apply in an upper secondary school context; for example, the implementation of ideas involving crossfertilization with other organizations and cultures was rare. In order to learn new pedagogical practices, teachers need organized time for collaborative planning, for reflecting, and for sharing.
\end{abstract}

\section{Introduction}

Teachers' professional learning is regarded as one of the key issues for a well-managing school and for improving students' learning outcomes (e.g., [1]), although the connection is complicated and not always true [2-5]. At the moment, studies [4] and policy-papers [6] emphasize the need for a shift from a teacher-centred to a student-centred approach as a key learning need for teachers in order to enhance students' necessary future competencies, such as constructive collaboration, knowledge searching and application, and solving complex problems. The teacher-centred approach focusing on an individual student's learning of mere academic knowledge does not support the development of these skills [6-8]. It is challenging for teachers, but also for schools, that complex knowledge work competences evolve only through extensive, repeated, versatile, collaborative, and long-term practising, which should be enabled in varying instructional contexts throughout a student's studies $[9,10]$. Traditional subjectbased curricula and the idea of teaching as delivering information are strongly opposite to this. In this case study, the aim is to investigate how teachers adopted theory-based pedagogical practices which focus on improving students' collaborative knowledge work competencies.

In this article, we use the specific term "teacher (professional) learning," following the examples of Opfer and Pedder [11] and Admiraal et al. [12] instead of teacher professional development because of the connotations; the second term often tends to emphasize individual teacher's learning. We strongly relate teacher learning at the workplace to both individual and collaborative practices and we emphasize individual and collaborative teacher learning as core processes required in the professional development of teachers and the development of schools. Teacher learning can be seen as changes in their conceptions and further in their pedagogical practices. At the workplace, learning and working are 
intertwined, although the ways of organizing learning or the learning goals may vary. In our study, the focus is on teacher learning that takes place within the context of a development project, but, of course, also during teachers' work with their students, during informal discussions and other situations, which emerged during the project's life time.

Teachers' professional learning at workplace can be facilitated in several ways and by various methods, but as Opfer and Pedder [11, p. 381] state in their review, "we assume that in different combinations, circumstances, and sequences, the same causes that may produce teacher learning and change may also lead to intellectual stagnation and inertia." Kennedy [13] emphasizes that, with different conceptions of teaching and teacher's role, researchers have different conceptions of how teacher learning can improve teaching, and there is not any single theory that comprehensively describes teacher learning. Teacher professional learning is a systemic phenomenon taking place in multiple surroundings and interactions (cf. [14]), in which not only teachers as individuals but also teacher teams, school, and educational organizations influence the learning outcomes. In addition, it is not an individual event but a complex process in which the various levels of the system affect each other [11]. The levels consist of very different issues which influence the teacher's professional learning. An individual teacher has his/her previous experiences and beliefs of teaching and learning, teacher teams might inspire individual teachers to improve their professional expertise, similarly a school's structures, norms, and practices either support or prevent this process, and the local as well as national educational organizations provide resources but also requirements for schools and individual teachers for professional learning. Schools have a strong influence in the professional learning of teachers [3, 13]. Schools that support a sense of competence, autonomy, and collegiality among teachers tend to have teachers who are motivated to make drastic changes to their traditional teaching approaches [15] and the relationship is reciprocal: individual teachers contribute to schools and their development [16].

The characteristics of effective teacher learning are not straightforward or simple, and in her review concerning extensive professional development programmes, Kennedy [13] suggests that programme design features may be unreliable predictors of programme success. The fruitfulness of design features such as content, collective participation, or how intensively coaching programmes are used can have both positive and negative effects, depending on how they are organized (see also [11]). Several studies focusing on teachers' learning agree about the main characteristics of effective methods to facilitate it. Learning should have a content focus and it should be coherent so that it is consistent with teachers' knowledge and beliefs [17], and the learning practices should be job-embedded and practical, such that teachers should have everyday support at the workplace available; collegial and collaborative [2, 3, 16-19] which Admiraal et al. [12] described as teachers sharing their practices, collaborating, and reflecting upon their teaching practice; interactive and active meaning that learning should consist of active involvement and handson activities [17, 19]. In addition, the learning activities should be intense and sustained, not short-term sporadic events [2, 3, 17]. Peer support has been shown to be an effective means for teaching [18] and an essential element for co-teaching in inclusive settings [20]. Jones and Vincent [21] reported the results of how supervised colleagues mentored the use of Interactive White Boards (IWBs) and Lakkala and Ilomäki [22] reported findings where a peer mentor helped reduce teachers' fear of technology use and its unexpected consequences in the classroom.

The present study was conducted in a Finnish upper secondary school that participated in an international development project KNORK (Promoting Knowledge Work Practices in Education) [23] as a partner for pedagogical experimentation. In Finland, formal and informal requirements for an individual teacher's learning have been expressed at various levels of educational administration. At the national level, several major changes are going on in Finnish upper secondary schools. The matriculation examinations are being changed to be completely electronic during the years 2016-2019, which put the schools under pressure. Among teachers this has led to a need to digitalize learning environments and teaching as well as to improve teachers' general digital competence even more. Simultaneously, a new Core Curriculum for General Upper Secondary Schools has been implemented in Finland. In addition to traditional academic subject knowledge and skills, it emphasizes integrated thematic entities of various subjects, inquiry and problem approaches, information processing skills and student collaboration, multiliteracy, and media [24, pages 34-39].

The theoretical basis of this study for pedagogical development lies in the trialogical learning approach (TLA) [25, 26] on which also the KNORK project was created. The trialogical approach aims to promote pedagogical processes where students focus their efforts on developing concrete knowledge-laden artefacts together. In addition, the KNORK project focused on using new digital technology to support the aimed pedagogical practices.

To explicate the core idea of TLA and to support educators in designing their pedagogical practices according to the approach, a set of trialogical design principles (DPs) has been proposed [26]. The DPs can be applied in varying ways and degrees in pedagogical design; they are generic guidelines rather than detailed rules. Their purpose is to guide educators in designing educational settings and learner activities in a way that supports the learning of collaborative knowledge creation competences in addition to domain-specific content learning. The six DPs are the following:

DP1: Organizing Activities around Shared "Objects." Learner tasks and activities include collaborative working on improving tangible shared objects (plans, reports, media products, etc.).

DP2: Supporting Integration of Personal and Collective Agency and Work through Developing Shared Objects. Tasks and working criteria are designed so that learners have to take responsibility for their own efforts as well as advancing shared goals and tasks. In an ideal situation, the requirements combine individual goals with collective goals. 
DP3: Emphasizing Development and Creativity in Working on Shared Objects through Transformations and Reflection. The phenomena are examined by using different forms of knowledge and artefact types (theoretical constructs, practical working, problem solving, discussions, various media types, etc.) as well as by engaging in continuous reflection of practices and outcomes.

DP4: Fostering Long-Term Processes of Knowledge Advancement with Shared Objects. Developing shared objects takes place in sustained, prolonged, and iterative working processes. The goal is to develop outcomes and practices that have real importance and further use for the learners' or other stakeholders.

DP5: Promoting Cross-Fertilization of Knowledge Practices and Artefacts across Communities and Institutions. Fruitful learning practices include influences from external communities and organizations and collaboration between participants from different groups and institutions, for example, students' collaboration with professionals in working life.

DP6: Providing Flexible Tools for Developing Artefacts and Practices. Modern digital tools are used purposefully and effectively to support collaborative work on shared objects as well as to enable flexible mobility and coconstruction in various representational forms.

In this study, we focus on organized possibilities for teachers' workplace learning within a pedagogical development project, in which the project and its theoretical basis formed a framework for teachers' professional learning. The learning object for teachers was the theory-based trialogical approach and the guiding design principles to be adopted and applied in the teachers' own teaching.

\section{Aim and Research Questions}

In this study, teacher learning was investigated in the following areas: participation in the project, adopting and applying new pedagogical practices, and experienced challenges and benefits during the project. This outline locates the study in the activities of teacher learning, not in individual teachers' beliefs or in the school as an organization (see [3]).

The research questions are the following:

(1) How did the teachers participate in the project?

(2) How did the participating teachers adopt and apply the trialogical approach in their pedagogical practices?

(3) What kinds of challenges and benefits did the participating teachers experience during the implementation of the trialogical approach?

\section{Method}

The study is an explanation building case study [27], which emerged during a pedagogical development process in an upper secondary school through participation in the international KNORK project. The professional learning for improving and even changing previous practices formed the case. The study resembles an ethnographic study: we explored the characteristics of a social phenomenon instead of testing hypotheses and the focus was on a detailed study of one case $[28,29]$. Through a combined use of qualitative data of the teachers' pedagogical development process and quantitative data from students' questionnaire, we examined a specific phenomenon: teachers' professional learning which emerged especially in their changed pedagogical practices during the project.

3.1. Participants and Sampling Procedures. The upper secondary school under study is located in a Helsinki suburb in Finland. It has 583 students and 54 teachers. The school follows the basic upper secondary curriculum and, besides that, it implements a special curriculum emphasizing media arts. The school has been active in various kinds of ICT and development projects. The main participants of the study are those teachers of the school who contributed in the project work and filled the timesheets which teachers used to report for the project what they had done. Altogether 13 subject teachers (24.1\% of all teachers) completed the timesheets; ten of them were females and three were males. The age varied from 27 to 59 , and the mean was 42.0 , SD 0.9, and median 42. All participants have a teacher education background and master level university degree in the subjects they teach which are the competence requirements for subject teachers in Finland. The participants taught the following subjects: life philosophy and philosophy (1 teacher), religion, psychology, and media (1), mother tongue and literature or media (2), mathematics, physics and chemistry, and information technology (3), biology and geography (2), history and civics (2), and English (2). Except for one participant, all had full-time permanent work contracts, but a few of the full-time teachers had one-year work contracts (which were renewed yearly). All teachers in the school were invited to participate in the KNORK project and in the related study and both in the project and in the study. Based on the project funding, the school had some extra financial resources for teachers' activities, for example, for substitute salary costs when teachers took part in projectrelated work. However, teachers were not paid for participating in the study.

Altogether 147 students participated in four closely investigated courses (energy in ecosystem, cultural geography, democracy and human rights, and nature and the meaning of religion) and 79 of them (53.7\%) participated in the study by answering a Contextual Knowledge Practices (CKP-School) questionnaire [30] at the end of the course. The mean of their age was 16.9, SD 0.9, and median 17; 41 were females $(52.5 \%)$ and 38 were males. A questionnaire was given to all participants of the closely investigated courses, and it was voluntary for the students to fill and return it.

3.2. Measures. For the data collection, we used a mixed methods approach: seven instruments were used to collect data, aiming at creating a multifaceted understanding of the case 
and presenting the diversity of the emergence of professional learning [31]. These various types of data helped us to understand the complex phenomena [32] and to actualize triangulation. The data were collected during the project lifetime, starting from the first workshop in January 2014 and ending till the end of the last activities in May 2016, and organized into a database, following the principles of case study research [32].

(1) Timesheets of the Project. Teachers kept timesheets for EUreporting about participating in project activities, both the number of hours and the nature of participation (e.g., participation in a workshop or planning a course together with another teacher). The data were collected at the end of the project. The timesheets were used to answer the first research question.

(2) Teachers' Plans for the Course Improvement or for a New Course. The plans were created as Google Docs during project workshops and they were shared to all participants; they were available also after the workshops. Altogether 14 plans were created in groups and one plan was created by one teacher. All the plans were not completed, but teachers could later on use the ideas during another course. The plans were produced throughout the project and collected for the analysis at the end of the project. The data were used to answer the first and second research questions.

(3) Observations of the Lessons of Several Courses and Additional Materials Used during the Lesson or Course. Researchers observed 1-3 lessons of some courses; observation notes of five courses were used in the study. The observation notes followed a preplanned template of the pedagogical practices (that is, what the teacher and students did; see [17]), framed by the trialogical approach. The observations were conducted during each course, from spring 2014 till spring 2016. The data were used to answer the second research question.

(4) Teachers' Postinterviews. Teachers were interviewed in groups after their courses (one teacher answered the questions by email). Altogether six interviews were carried out, and 18 teachers participated in them (some of them twice). These focused on the pedagogical changes of their courses. The data were collected during the project lifetime, from spring 2014 till spring 2016. The interviews were used to answer the second and third research questions.

(5) Teachers' Descriptions of Their Courses in the KNORK Website. Some of these were written together with the researchers. Altogether there were five descriptions (energy in an ecosystem, game culture and media entrepreneurship, voluntary work, comparing the idea of human rights in various historical declarations, and Blogger). The data were produced from spring 2014 till spring 2016 and collected for the analysis at the end of the project. The data were used to answer the first and the second research questions.

(6) Teachers' Reflections by Email. The email questions focused on the pedagogical changes, successes, and challenges. These were collected during the revised or new courses (seven teachers) or after the courses (one) in spring 2015. The data were used to answer the second and third research questions.

(7) Students' CKP Questionnaire. The Collaborative Knowledge Practices (CKP-School) questionnaire [30] was used to measure the learning of generic competences related to collaborative knowledge work with 7 scales: collaborate on shared objects (S1), integrate efforts (S2), feedback (S3), persistent development (S4), combining perspectives from different subjects (S5), collaboration with experts outside the school (S6), and exploit technology (S7). We report data from four courses (one course data set was not collected), where students responded to the questionnaire at the end of their course. They were asked to assess on a scale from 1 ( $=$ not at all) to 5 (= very much) how well each statement corresponded to what they had learnt: "During the course I have learned...," for example, "to define sub-goals for the collaborative work" and "to use technology to advance collaborative work." Students responded to the paper questionnaire in class and provided an informed consent.

3.3. Research Design. Because the study was conducted in the context of a European-level project and the phenomenon, teacher learning, emerged during the project lifetime, the research was designed to follow the project activities. A methodological solution followed the researchers' previous case studies [22] in which lessons of voluntary teachers are observed and the same teachers are interviewed after their courses, either in groups or by email. In addition, teachers' outcomes during the educational interventions (= guided creation of plans and descriptions of the courses in the KNORK website) were also collected. Because teachers participated differently, they were observed and interviewed after their activities individually, in pairs or small groups.

Seven courses were observed but because two of them were run by the same teachers, only one course of each teacher was selected. The selected courses were obligatory for the students, and they represented various subjects. These courses were selected because they all contained improvements based on TLA. The analysis focused on the TLA-based practices.

The observed courses were the following.

Energy in Ecosystem. This was a new integrated unit of three courses of biology, chemistry, and physics. Three teachers created an integrated unit based on phenomenon-based learning [33]. Energy is discussed in all the courses, but from different viewpoints. The aim was that with a common theme, the students would get a larger overall understanding about energy and also learn some generic working competencies. The courses were conducted in the same manner as previously, but there was one common collaborative inquiry assignment "energy in an ecosystem" for the students. The courses lasted seven weeks and the energy project took one-third of the time scheduled for the courses. Students (approx. 70 in all) worked also at home for the project. The energy project started with a joint brainstorming session about the phenomena. Students formed groups within each course based on their interests in 
the subtopics, so the courses were not mixed between courses. The groups had a task to investigate one issue about the common theme. An expert from a solar system company participated in the process by giving an expert lecture to the students in the middle of the project. Google documents were used for sharing and coauthoring material, and the final product was constructed as a Prezi presentation. This was the second implementation of the integrated entity and teachers had made some changes based on the experiences of the first one.

Comparing the Idea of Human Rights in Various Historical Declarations (History). The TLA-related assignment during the history course was part of a larger human rights project, taught in several courses. One issue in the national curriculum of the course was to understand the emergence of human rights and equality. Students should, for example, learn to evaluate the emergence of various ideals and ideologies and their influence in the world. At the beginning of the courses, almost all students followed an introductory lesson about human rights given by an external expert from the United Nations Association of Finland. For the history component, the teacher had organized assignments for group work before the course started, and he formed five groups of 3 to 4 students. The aim was to seek answers to the question about how human rights have actualized during the three phases in history. The groups were newly formed for every phase. The students (18) used three lessons (75 minutes each) for doing the group work. The groups used Google Sites as an environment into which they produced their work; each group had a virtual page they could use.

Democracy and Human Rights (Civics). The TLA-related assignment during the civics course was also a part of human rights. The learning goals were connected to the aims of the national curriculum, to understand the welfare state, individual rights, and duties and get interested in influencing in society. These students followed an introductory lesson about human rights given by an external expert from the United Nations Association of Finland. During the course, students studied various topics of democracy, for example, human rights in Europe, decision-making in the Finnish Parliament, and issues of the welfare state. Students (15) worked in four groups of three-four students. First they studied an entity of human rights individually at home. At school, each group became familiar with two cases of the European Court of Human Rights and made a short presentation about the cases. The aim was to publish them in a blog for all courses of human rights but only two cases were published. Teacher gave feedback to groups and they improved their descriptions. The students used three lessons (75 mins each) for the course; they followed the expert lecture and did the homework for this entity. Groups used the school's VLE, Padlet, and Blogger for their work.

Cultural Geography (Geography). This course involved students doing tasks on various phenomena concerning cultural geography, such as population growth and developing countries. In the national curriculum, the content of the course consisted of understanding the effects of human beings in the world. The teacher emphasized that the aim is to get students to talk also about the values involved. Students had six tasks which the teacher had modified and improved based on the tasks in the textbook; students had to search for and apply their knowledge to answer the questions. The tasks became progressively more difficult during the course and the last task was a larger summary of the issues studied during the course; students used three lessons for it ( 75 mins each) and they also did it at home. The teacher gave feedback to improve the outcome. Students (21) worked in small groups or individually according to their preferences. The students worked in a VLE and reported their findings with Google Docs which they shared with the teacher. This course had probably fewer improvements than the other ones because it was taught for the last time (not part of the new curriculum).

Nature and the Meaning of Religion. Students (25) worked in groups of 3-4; the groups were formed by the students. Each group chose one religion which they then investigated based on the question "How is sacred manifested in that religion?" Each member had an issue to prepare and present within their own group. After that the students rearranged the group members using jigsaw methods so that in the new groups all the religions were represented. The outcome of the course was a set of PowerPoint presentations about what is sacred in various religions. Students also evaluated their outcomes themselves and the outcome was source material for an individual essay. The teacher used an assignment from a virtual book which the teacher had revised. Students used Google Docs and presentation tools which they shared within their groups and with the teacher.

The data were collected during the project lifetime as follows.

April-June 2014. Data collection (plans, observations, postinterviews, and students' questionnaires) was from the first course (energy in an ecosystem).

January 2015. Data collection was from the school-level workshop and plans written by the teachers.

February-May 2015. Data collection (plans, observations, postinterviews, and students' questionnaires) was from four courses (energy in ecosystem, voluntary work, democracy and human rights, and comparing the idea of human rights in various historical declarations).

January-March 2016. Data collection (plans, observations, postinterviews, and students' questionnaires) was from two courses (nature and meaning of religion and chemistry).

April-May 2016. Last teacher interviews concerning the experiences of the project were done.

3.4. Educational Interventions. In this study, support for teachers' learning at the workplace was connected to a pedagogical project in which the researchers had three kinds of roles. First, they were researchers collecting data for the study. Second, they had a scaffolding role to persuade teachers to 
adopt theories and practices while the participating teachers themselves applied the pedagogical approach and the practices in their classrooms. Third, they had roles as project managers organizing and supporting the project-level activities; also in this role, they guided the teachers and the school. The participation in the project as a partner is not a typical or ordinary activity for schools, and although the school in question had participated in various projects before and it had external networking, not only were the teachers learning and applying new pedagogical practices but many of them were also participating in a project with external partners for the first time [34].

The interventions which influenced teachers' plans and classroom activities ( $=$ the KNORK project-level activities in school) are presented in Table 1. In general, the interventions were collaborative planning meetings or teacher workshops in which several teachers created new courses or improved existing courses based on theoretical guidance and practical feedback.

3.5. Data Analyses. The data analysis relied on theoretical propositions: the objectives and the research questions formed the basis for the data analysis [27].

Analysis of Teachers' Participation in the Project. The analysis of teachers' participation in the project is based on (1) timesheets of teachers' participation in the project, (2) teachers' postinterviews, and (3) teachers' reflections by email. The timesheets showed how many hours teachers used for project activities as well as in which activities they had participated. The amount of time was divided into two categories: more than 20 hrs and less than 10 hrs. Further, the postinterviews and teachers' reflections by email were screened to identify all the TLA-related courses and the other activities related to the project. Finally the teacher participants were divided into three groups based on the number of TLA-related courses and the length of participation in the project.

Analysis of the Implementation of Trialogical Design Principles. The analysis of the implementation of trialogical design principles is based on (1) observations of the lessons of some courses and additional materials used during the lesson or course, (2) teachers' postinterviews, (3) teachers' descriptions of their courses in the KNORK website, (4) teachers' reflections by email, and (5) students' CKP-School questionnaire answers.

For in-depth analysis, five courses were selected because the data of these courses was rich and consisted of many types of data. For the analysis, we first created a description of each course using the various data sets, concentrating on elements which are relevant for the trialogical design principles. After that, a theory-driven qualitative analysis [35] of each course was conducted based on the design principles. Three researchers created a table of the design principles and the description of activities of each case. (See the example of the course energy in ecosystem in Table 2.)

After that, the researchers together made an in-depth analysis of the activities in each design principle aiming to categorise the level of activities (see Table 3). The researchers' interpretations were compared with the participants' evaluations of the implementation of DPs and other pedagogical practices, expressed in the interviews. The researchers' interpretations were revised to a final description of practices for illustrating the implementation of each DP. The levels which were used to represent the implementation of DPs in the courses are shown in Table 3.

Based on the postinterviews and email reflections, we also analysed teachers' descriptions of other courses that they had conducted (besides the five intensively investigated ones) and new ideas and future plans for applying TLA because these also describe how the trialogical design principles were adopted.

These results are shortly reviewed in the results.

Analysis of the Experienced Challenges and Successes. Teachers' postinterviews and their reflections by email concerning the experiences, challenges, and successes during the project were first transcribed and then analysed with ATLAS.ti using qualitative content analysis. The following main categories were defined.

(i) Challenging: subcategories are general challenges (e.g., not enough collaboration with other teachers) and challenges in the teacher's course (e.g., the assignment was all too difficult and when it was time to work, the groups did not work).

(ii) Successes: subcategories are general successes (e.g., [students learnt] collaboration skills, planning of a joint project, and delegating tasks) and successes in the teacher's course (e.g., it was nice that it was possible to concentrate to one (very essential) topic somewhat more).

(iii) Learnt: when teachers reported their challenges and failures, they also often mentioned how what they had done could have been done better (e.g., a challenge is also to make the blog more known, otherwise it just disappears in the "cloud"). These comments were coded to Learnt.

\section{Validity and Reliability of the Study}

The data were collected over 2.5 years which meant a prolonged stay for the researchers in the school. Teachers and the school practices became familiar to the researchers, and too hasty interpretations could be avoided. The construct validity was ensured by using multiple sources of evidence (data), which were used to strengthen the conclusions, and through collaborative writing (teachers and researchers together) about the experiences for the project website. In order to ensure internal validity, interpretations of the results were discussed by three researchers, and to ensure reliability, a database of the evidence was created which was updated constantly during the analysis process. In addition, for quantitative data, a previously developed questionnaire was used, and a qualitative content analysis procedure was followed for interviews and emails. 
TABLE 1: Project-related activities during the end of 2013-June 2016.

\begin{tabular}{|c|c|c|}
\hline \multirow[t]{2}{*}{2013} & Autumn & $\begin{array}{l}\text { A presentation in the teachers' meeting. It consisted of describing the project as well } \\
\text { as the trialogical learning approach. }\end{array}$ \\
\hline & December & A planning meeting was organized in the school with a few teachers. \\
\hline \multirow[t]{2}{*}{2014} & January & $\begin{array}{l}\text { KNORK kick-off meeting, including a workshop for planning the first courses. } \\
\text { Three teachers and the principal participated. }\end{array}$ \\
\hline & November & Teacher meeting in the school for inspiring new teachers to participate. \\
\hline \multirow{3}{*}{2015} & \multirow{3}{*}{ January } & $\begin{array}{l}\text { KNORK Consortium meeting and a theory-driven pedagogical workshop. Two } \\
\text { teachers participated (one coordinator, one of the teachers who was in the kick-off } \\
\text { meeting) }\end{array}$ \\
\hline & & $\begin{array}{l}\text { Theory-driven workshop for all teachers in the school ( } 42 \text { participants): the } \\
\text { researchers provided the teachers with a design template for improving their } \\
\text { courses based on the TLA approach. Teachers were encouraged to collaborate with } \\
\text { each other in redesigning courses or creating new courses. }\end{array}$ \\
\hline & & $\begin{array}{l}\text { A follow-up of the previous workshop; guiding teachers to continue their plans. } \\
\text { Several teachers participated, mainly those who had implemented some course } \\
\text { designs that had been planned before. }\end{array}$ \\
\hline 2015 & $\begin{array}{l}\text { August- } \\
\text { November }\end{array}$ & $\begin{array}{l}\text { Guiding teachers to write descriptions of courses or tools on the project pages based } \\
\text { on a common template (energy in an ecosystem, comparing the idea of human } \\
\text { rights in various historical declarations, and Blogger). Researchers participated as } \\
\text { coauthors and editors in the writing process. }\end{array}$ \\
\hline 2015 & November & $\begin{array}{l}\text { Organizing a reflection workshop. The courses were reflected based on students' } \\
\text { self-evaluation results collected with the Collaborative Knowledge Practices } \\
\text { (CKP-School) questionnaire [32] presented by the researchers. Discussions of } \\
\text { future work. Several teachers participated. }\end{array}$ \\
\hline 2015 & April & $\begin{array}{l}\text { A major national event where the researchers invited the school to participate and } \\
\text { present the project outcomes; one teacher participated. }\end{array}$ \\
\hline 2015 & April-May & $\begin{array}{l}\text { Guiding teachers to write descriptions of courses on the project pages (voluntary } \\
\text { work, game culture, and media entrepreneurship). }\end{array}$ \\
\hline
\end{tabular}

TABle 2: An example of activities describing DP1.

\begin{tabular}{ll}
\hline & One inquiry theme of 3 separate courses. \\
DP 1: organizing & Student groups had a research theme and all \\
activities around & groups created a collaborative outcome which \\
shared object & $\begin{array}{l}\text { was integrated into one large entity (Prezi } \\
\text { presentation) }\end{array}$ \\
\hline
\end{tabular}

\section{Results}

5.1. Teachers' Participation in the Project. Based on the analysis, three groups of teachers were formed: a pilot group, a group of active adopters, and adopters.

The first teacher group-three teachers-participated in the first international workshop; they were the first ones who announced their interest in the project to the principal. One of them also participated in the second international workshop, and they all participated actively in the school-level workshops and activities during the project lifetime. They also received various kinds of informal individual guidance from the researchers related to their new pedagogical practices after the observation sessions as well as after the interviews. They were a sort of pedagogical core of teachers during the 2.5 years of the project, the pilot group, and two of them also participated in a new research project which started during the last months of the KNORK project. These teachers together taught an integrated thematic entity, "energy in an ecosystem" three times, and they also adopted some of the trialogical practices in their other individual courses.

At the second half of the first year, one of the teachers in the school started to coordinate the school-level activities. As a consequence of this, the school-level workshops were organized, which, in turn, activated new teachers to learn about and apply the project's pedagogical approach. The first workshop in the school was the basis for the development work since teachers created their pedagogical plans with Google Docs, and they shared these with all the other teachers. One teacher group created a large thematic entity "human rights" which was organized through a collaborative blog tool, Blogger, and teachers connected their courses to this theme as they saw fit; some planned more activities, some less; they also applied the design principles differently for their courses.

During the second year, there was the emergence of five teachers who could be called the group of active adopters. All these teachers were involved in "human rights" and they also continued to apply the design principles to other courses. They all wrote a description of their courses for the public pages of the KNORK project, one of them wrote a blog post and presented the project in a large national ICT in education conference, and three of these teachers participated in the international workshops and the final conference of the project in which they presented their courses. In addition, one teacher started to participate actively at the project in the end of the second year, after her maternity leave. This teacher 
TABLE 3: The analysis framework of the investigated courses.

\begin{tabular}{|c|c|c|c|}
\hline & $\mathrm{De}$ & he application of the DP & \\
\hline & Level 1 & Level 2 & Level 3 \\
\hline $\begin{array}{l}\text { (1) Organizing activities } \\
\text { around shared "objects" }\end{array}$ & $\begin{array}{l}\text { Answers to teacher's } \\
\text { questions: every individual } \\
\text { or a group answered the } \\
\text { same questions and the } \\
\text { answers were then shared }\end{array}$ & $\begin{array}{l}\text { Group work and a joint } \\
\text { object: the improvement is } \\
\text { based on division of labour; } \\
\text { only limited collaborative } \\
\text { improvement }\end{array}$ & $\begin{array}{l}\text { Groups had a collaborative } \\
\text { object for their work: } \\
\text { sharing and versioning } \\
\text { were a collective } \\
\text { responsibility }\end{array}$ \\
\hline $\begin{array}{l}\text { (2) Supporting integration } \\
\text { of personal and collective } \\
\text { agency and work through } \\
\text { developing shared objects }\end{array}$ & $\begin{array}{l}\text { Either individual or group } \\
\text { work but the agency for } \\
\text { these was not integrated }\end{array}$ & $\begin{array}{l}\text { Individual and group work } \\
\text { somewhat integrated; for } \\
\text { example, an individual } \\
\text { writing task following the } \\
\text { group work and based on it }\end{array}$ & $\begin{array}{l}\text { Individual and group work } \\
\text { integrated; for example, } \\
\text { group outcomes are } \\
\text { constructed from } \\
\text { individual contributions }\end{array}$ \\
\hline $\begin{array}{l}\text { (3) Emphasizing } \\
\text { development and creativity } \\
\text { in working on shared } \\
\text { objects through } \\
\text { transformations and } \\
\text { reflection }\end{array}$ & $\begin{array}{l}\text { Versioning or different } \\
\text { types of information not } \\
\text { used, no reflection }\end{array}$ & $\begin{array}{l}\text { Versioning during the } \\
\text { process but only limited } \\
\text { reflection, for example, } \\
\text { only by the teacher, or } \\
\text { examination of various } \\
\text { types of information }\end{array}$ & $\begin{array}{l}\text { Multiple ways of versioning } \\
\text { and reflecting by peers and } \\
\text { the teacher, for example, } \\
\text { mind maps for } \\
\text { brainstorming, } \\
\text { collaborative writing, and a } \\
\text { presentation }\end{array}$ \\
\hline $\begin{array}{l}\text { (4) Fostering long-term } \\
\text { processes of knowledge } \\
\text { advancement with shared } \\
\text { objects }\end{array}$ & $\begin{array}{l}\text { Mainly one lesson-two } \\
\text { lessons; no reuse of the } \\
\text { outcomes }\end{array}$ & $\begin{array}{l}\text { Longitudinal process, for } \\
\text { example, time used } \\
\text { regularly during a course; } \\
\text { no reuse of the outcomes }\end{array}$ & $\begin{array}{l}\text { Longitudinal process, for } \\
\text { example, time used } \\
\text { regularly during a course; } \\
\text { reuse for other activities } \\
\text { supported }\end{array}$ \\
\hline $\begin{array}{l}\text { (5) Promoting } \\
\text { cross-fertilization of } \\
\text { knowledge practices and } \\
\text { artefacts across } \\
\text { communities and } \\
\text { institutions }\end{array}$ & $\begin{array}{l}\text { No cross-fertilization; } \\
\text { however, authentic } \\
\text { (Internet) sources bring } \\
\text { some external influences }\end{array}$ & $\begin{array}{l}\text { Some cross-fertilization } \\
\text { conducted but not } \\
\text { integrated into the course } \\
\text { work, for example, an } \\
\text { external visitor }\end{array}$ & $\begin{array}{l}\text { Cross-fertilization between } \\
\text { subjects or external visits } \\
\text { integrated in the course } \\
\text { work, for example, } \\
\text { prepared questions to the } \\
\text { expert and postreflection of } \\
\text { the expert's answers }\end{array}$ \\
\hline $\begin{array}{l}\text { (6) Providing flexible tools } \\
\text { for developing artefacts and } \\
\text { practices }\end{array}$ & $\begin{array}{l}\text { Basic office tools and the } \\
\text { Internet in use but not used } \\
\text { for collaboration }\end{array}$ & $\begin{array}{l}\text { Multiple tools, also } \\
\text { collaborative, but the use is } \\
\text { limited, for example, } \\
\text { sharing only between the } \\
\text { teacher and each group }\end{array}$ & $\begin{array}{l}\text { A rich variety of tools, used } \\
\text { meaningfully, for example, } \\
\text { students' mobile phones } \\
\text { used for recording and } \\
\text { brainstorming or mind } \\
\text { maps tools and } \\
\text { collaborative tools }\end{array}$ \\
\hline
\end{tabular}

could probably have been an active adopter if the project had not run out of time.

After the first school-level workshop, five teachers became adopters; they adopted some aspects of the presented trialogical practices and they participated somewhat in school-level workshops and collaborated with other teachers, but they were not especially active at the project level. However, they also introduced some inspiring pedagogical renovations, some of which had their origin in the first workshop organized in the school.

There were also teachers who participated in the first workshop in the school, but who did not start any major trialogical processes with students; even though they might have applied some elements of the pedagogical approach in their individual teaching, they did not collaborate with other teachers. Information about these individual cases was shared with the researchers informally, for example, during lunch break discussions.
5.2. Trialogical Design Principles Applied and Adopted by the Participating Teachers. To answer the second research question on how design principles of TLA were applied and adopted, we present the results for (1) five investigated courses and (2) other examples of courses with trialogical characteristics, and then we give examples of (3) teachers' future plans for applying TLA.

Implementation of Trialogical Design Principles in Five Courses. Five investigated courses were evaluated based on the characteristics of pedagogical practices from the viewpoint of trialogical design principles. The teachers of these courses were either pilot teachers or active adopters. Table 4 shows the level of the design principles applied.

In all the investigated courses, the use of digital technology was of a high level: teachers used meaningful and appropriate applications. Supporting the integration of personal 
TABLE 4: The level of trialogical design principles applied in five courses.

\begin{tabular}{|c|c|c|c|c|c|}
\hline $\mathrm{DP}$ & $\begin{array}{l}\text { Energy in } \\
\text { ecosystem }\end{array}$ & $\begin{array}{l}\text { Democracy and } \\
\text { human rights }\end{array}$ & $\begin{array}{l}\text { Comparing the } \\
\text { idea of human } \\
\text { rights }\end{array}$ & $\begin{array}{l}\text { Cultural } \\
\text { geography }\end{array}$ & $\begin{array}{l}\text { Nature and the } \\
\text { meaning of } \\
\text { religion } \\
\end{array}$ \\
\hline (1) Organizing activities around shared "objects" & 3 & 3 & 2 & 1 & 2 \\
\hline $\begin{array}{l}\text { (2) Supporting integration of personal and } \\
\text { collective agency and work through developing } \\
\text { shared objects }\end{array}$ & 2 & 2 & 1 & 1 & 2 \\
\hline $\begin{array}{l}\text { (3) Emphasizing development and creativity in } \\
\text { working on shared objects through } \\
\text { transformations and reflection }\end{array}$ & 3 & 3 & 2 & 2 & 2 \\
\hline $\begin{array}{l}\text { (4) Fostering long-term processes of knowledge } \\
\text { advancement with shared objects }\end{array}$ & 2 & 2 & 2 & 2 & 3 \\
\hline $\begin{array}{l}\text { (5) Promoting cross-fertilization of knowledge } \\
\text { practices and artefacts across communities and } \\
\text { institutions }\end{array}$ & 3 & 2 & 2 & 1 & 1 \\
\hline $\begin{array}{l}\text { (6) Providing flexible tools for developing } \\
\text { artefacts and practices }\end{array}$ & 3 & 3 & 3 & 3 & 3 \\
\hline In all & 16 & 15 & 12 & 10 & 13 \\
\hline
\end{tabular}

and collective agency and work through developing shared objects was the most difficult design principle to apply.

The courses differed from each other at the level of implementing the trialogical approach. Energy in ecosystem was a pilot course at the school and the investigated course was its second implementation. The result shows an integrated entity in which teachers had applied TLA in a creative way and they were able to support the realization of all the design principles in an innovative manner. All these teachers were pilot teachers.

Democracy and human rights and comparing the idea of human rights in various historical declarations were some of the first iterations of TLA, and as such, they were well planned and both teachers succeeded in applying TLA for their topics at a relatively high level, although they had problems in the realization of their courses: in both courses the assignments were too challenging to be done within the given time (teachers' comments). The teachers also had problems in guiding group work. Both teachers were active adopters. Cultural geography was a course conducted for the last time; there was not enough interest to improve it significantly (teacher's comment). The teacher was one of the pilot teachers. Nature and the meaning of religion was a course based on a virtual textbook but was improved by the teacher by applying the TLA ideas at a high level; she had previously taught another course following the TLA ideas and she also applied those experiences to this course. The teacher was an active adopter.

Figure 1 describes students' self-evaluations given by CKP questionnaire where they commented on statements about which competencies they thought they had learnt during the course. The data is somewhat insufficient (we have no data from the course of comparing the idea of human rights in various historical declarations) but it shows in an interesting way how students' self-evaluations about learnt competencies are, in general, in line with the analysis of the trialogical

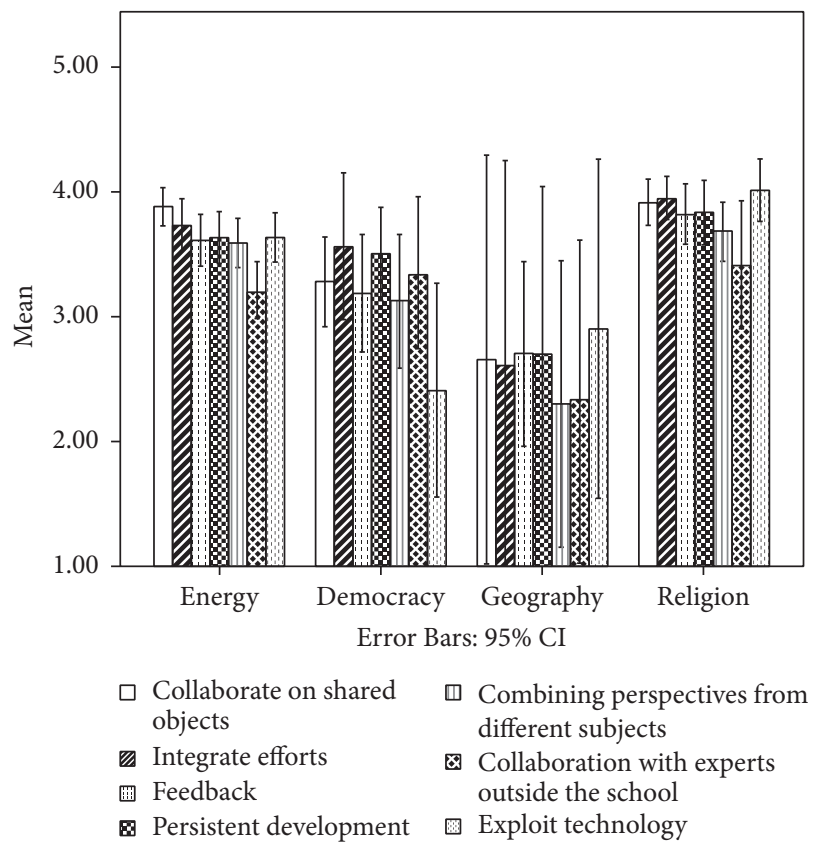

FIGURE 1: Students' self-evaluation of the competencies learnt during the courses.

design principles applied. Nature and the meaning of religion had the highest scores and energy in ecosystem had the second highest scores. Cultural geography had the lowest scores, and also its level of applied design principles was evaluated as modest.

Other Examples of Trialogical Characteristics in Courses. There were several other courses which had inspiring characteristics in the way of implementing the design principles and which were based on the ideas of the teacher workshops, for example, cross-fertilization with other institutes and cultures 
or sharing via a digital tool. Some examples of the courses are given below:

Literature is aiming to inspire students to read more. The teacher had invited an older lady-a very active reader-to talk virtually via Skype with students about reading. It was a good experience for the students, to hear about the benefits and experiences of reading fiction. The teacher was one of those who did not actively participate in the project.

Game culture and media entrepreneurship is a new course, created in late spring 2016 by the teachers of civics and Finnish language and literature; it was conducted together with a higher education institute. Students visited the other institute, external experts gave lectures during the course, and some students did their final work guided by the higher education institute lecturers. One of the teachers was an active adopter, and the other one was an adopter.

During an English course, students wrote fictional texts which were shared through a blog. The teacher was an adopter.

Voluntary work was a course which aimed at increasing students' understanding about voluntary work by activating students to participate in voluntary work. Students wrote a report about the organization among other issues and shared their experiences. The teacher was one of the active adopters.

Ideas and Future Plans for Applying TLA. Teachers had some new ideas about how to improve their own teaching; for example, "we could try the idea of "open doors," and we could visit what is going on in another classroom [to get] ideas also for own teaching," but one more important indicator about teachers' adoption of TLA was their plans for the future. In the interviews, teachers had the following new ideas for improvements to existing courses: adding more digital technology in the voluntary work course to support the sharing of the outcomes (active adopter); intentions to apply the ideas also to new courses (two active adopters, one adopter); an idea to widen energy in ecosystem, for example, to integrate also English language (one pilot teacher); continuing the entity of human rights and add teacher collaboration to the course (two active adopters), and continuing the game culture and media entrepreneurship course with a revised plan (a pair of active adopters and an adopter). There were also ideas about new integrated units: to realize the combination of several courses.

5.3. The Experienced Challenges and Successes Experienced during the Implementation of TLA. To answer the final research question, teachers' opinions about the challenges and successes of TLA implemented in the courses were collected with mid-reporting (emails) and final interviews or email interviews. The number of teachers who mentioned each issue is in parentheses.
Teachers' opinions about the challenges and successes were quite similar; there were, for example, no differences in the opinions regarding the teacher's activity in the project.

Teachers reported some general challenges which were common for the general implementation of TLA: the main shortcoming which the teachers mentioned was lack of sharing between the students, both within a course and beyond the courses (7). As the teachers mentioned, this was due to a lack of collaborative planning. The first planning workshop was a good start, but the teachers did not collaboratively plan the final details of the activities. So, the idea of sharing outcomes between students was not materialised. The other major shortcoming was the use of technology (4): first of all, the wireless network did not always work but also the blog application, used in the courses of human rights, was not very flexible in giving rights to users (it either gave all rights or only read rights). The third problem mentioned (4) was the timing of the integrated entities. They were organized during the last period of the school year which meant that students could not continue doing the assignments after the taught course. This was also the reason why sharing did not succeed: the outcomes were completed so late that they were useless for students of other courses. The problem of spending too much time on one activity (the planned activity of the trialogical approach) was mentioned by two teachers.

The challenges teachers felt in their own courses depended, naturally, on their previous experiences. The pilot teachers had experiences from two implementations and they had improved their operational practices from the first to the second one. They did not report many challenges: a kind of "permanent" challenge was the lack of time for the group work (two teachers), too limited integration because of the course structures (2), and the traditional structures of school work which do not support teachers' collaborating (1). The other teachers mentioned the following challenges: a lack of coordination in the human rights entity (2), problems with organizing the group work (2), students' poor digital competence (2), and too challenging tasks to complete within the time allocated (2).

Teachers had also many experiences of success. All three teachers running energy in an ecosystem mentioned that the start of the project succeeded well: students created good ideas and used the Padlet application and mobile phones to collect them. The teachers were able to guide this successfully; also the group formation succeeded well. Similarly, the expert lecture was good (all three teachers). The possibility of concentrating on one theme was good (2). One of the teachers mentioned the following: the group work results were good, the versioning succeeded well, and the digital applications used were good. Teachers teaching courses in the entity human rights course mentioned students' active participation as the best outcome; they discussed with and made active contact with students in other courses (4). As one teacher explained: "The students worked with pleasure, they returned [the assignment] in time. It was nice to do something else than usual basic work." Also, the use of digital technology succeeded well, and although, for example, the blog application was probably not the best one, teachers mentioned that they had learnt a new tool for sharing (3). Also, the group work 
outcomes succeeded (3). One of the teachers mentioned the following: cross-fertilization succeeded, and the goals were achieved (a model of integrating human rights into several courses) and disseminated in the school.

In the interviews and email reflections, several teachers talked also about issues that they had learnt during the project, things they should have done differently or which they regarded to be important for future implementations. The importance of collaborative planning was the main skill which teachers mentioned that they had learnt (six teachers) and six teachers also mentioned that they should have had more collaborative planning, also during their course implementations, not only before the course. As one of the teachers said: "I thought that we had planned it well but it wasn't... We should have planned the whole process." Although collaborative digital applications were new to some teachers and they encountered some problems, they (three teachers) also were satisfied: "[We] had to get familiar with information technology out of necessity, in a good sense." Individual teachers mentioned several pedagogical practices they had learnt: how to utilise external experts, how to guide a discussion, how to guide peer commenting, how to increase sharing, how to activate students, and how to make learning activities and outcomes visible. Two teachers also mentioned TLA: they still had questions about how to apply it. Teachers also mentioned the following organizational issues that they had become aware of: teachers should have had a distribution of work, and external structures are needed for pedagogical development work. As a concluding remark, one teacher said this about the project: "This has been good practice for developing a more collaborative working culture. However, there are still some structures that lead to extra work when implementing collaboration projects that involve several subjects, and because of this, it is understandable that only some teachers were enthusiastic about this new approach."

\section{Discussion and Conclusions}

In the study, we investigated teachers' participation in a pedagogical development project and whether teachers had learnt the theory-based trialogical approach by observing how they adopted and applied it into their own practices.

Teachers participated very differently in the project, but even well-organized professional learning does not always succeed as Coburn [36] explained this, as being due to dissonance: if new beliefs, practices, knowledge, and experiences are too different from teachers' existing ones, teachers may dismiss new ideas as inappropriate. For some teachers, the ideas of the trialogical approach might have been too far from traditional teaching or they demanded too many changes and too much teacher work. To apply new ideas and practices is a question of choice: education is noisy, as Kennedy [13] wrote, and there are various expectations and requirements for which a teacher has to create her/his individual working schema. It is also essential to take into account the fact that teacher communities are not stable entities. Teachers may take maternity leaves or have long sick leaves which may influence their participation in their schools' external activities; they may move to other schools or have long periods off for some other reasons; this was the case also in the investigated project. It is not possible to organize an ideal system of professional learning where everyone participates in designed training events and all the teachers share the same experiences in an agreed order.

We think that the participating teachers did learn: the implementation of the design principles was at a good level, teachers improved their practices from the first realization to the next ones, they cross-implemented ideas in other courses, and they also had ideas for the future. A good indicator of the progress made is the new kinds of courses which some teachers started to create and run. TLA was applied in a pedagogically creative way: teachers applied the theoretical ideas into their subjects, contexts, and administrative structures with those possibilities they had as individual teachers or teacher groups. This was also rewarded: in their assessments the students gave the new practices high scores, and they also participated actively during the lessons.

The trialogical design principles represented different pedagogical ideas and practices than what is usual in Finnish upper secondary schools; therefore adopting them required rethinking of learning and teaching ideas. The first implementations are often something between the previous and the new targeted practices, as noticed when revising higher education courses through the TLA [37]. Similarly, in the investigated school, the second implementations were improved versions of the first ones, just as were the teachers' new ideas for the future.

The theoretical approach, the trialogical approach, and the design principles are idealistic solutions for pedagogical practices and teachers need to apply the model (as they have to all other models) in their specific context. It is a creative process of combining a demanding theoretical approach and the existing practices; compromises and revisions are necessary. We may say that the implementations reveal teachers' learning and their pedagogical creativeness. During the project, the level of implementing the design principles differed. It was relatively easy to apply the idea of a shared object (DP1), using flexible technology (DP6) as well as the versioning of the outcome (DP3) into classroom practices. Integrating personal and collective agency (DP2) is demanding, for several reasons: the true agency requires motivation and interest in creating something new, and that might be sometimes missing in a regular classroom; this is in line with the comments of Paavola and Hakkarainen [25] when they asked for a new kind of agency. The reuse of outcomes (DP4) as well as cross-fertilization with other organizations and cultures (DP5) is rare, but not impossible in schools, as, for example, the experiences of the described courses show. To apply these DPs, teachers have to think about their pedagogical practices in a new way.

Teachers' missing collaboration was the one of the main challenges in the project; similarly the success of it was one of the benefits. The teachers' collaboration increased among the participants: they exploited the project's possibilities and actively valued the outcomes and new practices. For these teachers, the new collaboration culture was one of the important outcomes. Also, the nature of the active teachers' work changed: instead of lecturing, they had to organize external 
visits and visitors to the school, they had to facilitate student groups' learning activities in a new way, and they had to do much more collaborative preplanning than in previous courses-they were not used to and had not been aware of these new duties. These evolving practices as well as networking with external partners in a European-level project represented new models of professional learning [38].

In this project, the participating teachers and the school had external resources they could use to help learn the new practices, such as a school-level coordinator, researchers' workshops, payments for some extra work, and possibilities for European-level networking as well as other kinds of networking. It is obvious that such intensive support is not usually available. What is needed, in this school and in other schools, are structural changes at the school level. Teachers need organized time for collaborative planning, for reflecting, and for sharing. Because these are not traditionally included in a teacher's day-to-day activities, there will also certainly be resistance to change. These required changes will only be successful if they are part of school-level processes.

\section{Conflicts of Interest}

The authors declare that there are no conflicts of interest regarding the publication of this paper.

\section{Acknowledgments}

The study was partially supported by the EU-funded KNORK project (543154-LLP-1-2013-1-FI-KA3-KA) and ARONI Research Project (285806) funded by the Academy of Finland. The authors are very grateful to the principal of the school as well as to teachers and students who volunteered to participate in the study.

\section{References}

[1] OECD, Creating Effective Teaching and Learning Environments: First Results from TALIS, Organization for Economic CoOperation and Development, Paris, France, 2009, http://www .oecd.org/document/54/0,3343,en_2649_39263231_42980662_1_ 1_1_1,00.html.

[2] L. Darling-Hammond and N. Richardson, "Teacher learning: what matters?" Educational Leadership, vol. 66, no. 5, pp. 4653, 2009.

[3] D. Opfer and D. Pedder, "The lost promise of teacher professional development in England," European Journal of Teacher Education, vol. 34, no. 1, pp. 24-10, 2011.

[4] S. M. Owen, "Teacher professional learning communities in innovative contexts: "ah hah moments", "passion" and "making a difference" for student learning," Professional Development in Education, vol. 41, no. 1, pp. 57-74, 2015.

[5] F. Korthagen, "Inconvenient truths about teacher learning: towards professional development 3.0," Teachers and Teaching: Theory and Practice, vol. 23, no. 4, pp. 387-405, 2017.

[6] OECD, "The organisation for economic co-operation and development," in Are the New Millenium Learners Making the Grade? Technology Use and Educational Performance in PISA, OECD Publishing, Paris, France, 2010.
[7] C. Kiili, "Online reading as an individual and social practice," Jyväskylä Studies in Education, Psychology and Social Research 441, Jyväskylä University Printing House, Jyväskylä, Finland.

[8] L. Lundahl, I. Erixon Arreman, U. Lundström, and L. Rönnberg, "Setting things right? Swedish upper secondary school reform in a 40-year perspective," European Journal of Education. Special Issue: Knowledge, Globalisation and Curriculum, vol. 45, no. 1, pp. 46-59, 2010.

[9] R. Tierney, E. Bond, and J. Bresler, "Examining literate lives as students engage with multiple literacies," Theory Into Practice, vol. 45, no. 4, pp. 359-367, 2006.

[10] P. Goodyear and M. Zenios, "Discussion, collaboration and epistemic fluency," British Journal of Educational Studies, vol. 55, pp. 351-3368, 2007.

[11] D. Opfer and D. Pedder, "Conceptualizing teacher professional learning," Review of Educational Research, vol. 81, pp. 376-407, 2011.

[12] W. Admiraal, J. Kruiter, D. Lockhorst et al., "Affordances of teacher professional learning in secondary schools," Studies in Continuing Education, vol. 38, no. 3, pp. 281-298, 2016.

[13] M. M. Kennedy, "How does professional development improve teaching?" Review of Educational Research, vol. 86, no. 4, pp. 945-980, 2016.

[14] P. Tynjälä, "Perspectives into learning at the workplace," Educational Research Review, vol. 3, no. 2, pp. 130-154, 2008.

[15] S. Lam, R. W. Cheng, and H. C. Choy, "School support and teacher motivation to implement project-based learning," Learning and Instruction, vol. 20, pp. 487-497, 2010.

[16] J. Imants and K. Van Veen, "Teacher learning as workplace learning," in International Encyclopedia of Education, E. Peterson, E. Baker, and B. McGaw, Eds., pp. 569-574, Elsevier, 3rd edition, 2010.

[17] L. M. Desimone, "Improving impact studies of teachers' professional development: Toward better conceptualizations and measures," Educational Researcher, vol. 38, no. 3, pp. 181-199, 2009.

[18] I. Bakkenes, J. Vermunt, and T. Wubbels, "Teacher learning in the context of educational innovation: learning activities and learning outcomes of experienced teachers," Learning and Instruction, vol. 20, pp. 533-548, 2010.

[19] R. Fogarty and B. Pete, "Professional learning 101: a syllabus of seven protocols," Phi Delta Kappan, vol. 91, no. 4, pp. 32-34, 2010.

[20] J. Lehtonen, A. Toom, and J. Husu, “Teacher learning within co-teaching - moral aspects of practical knowledge in inclusive teaching," in International Perspectives on Inclusive Education. Volume 9: Ethics and Equity for Inclusive Education, A. Gajewski, Ed., Emerald Publishing, 2017.

[21] A. Jones and J. Vincent, "Collegial mentoring for effective whole school professional development in the use of IWB technologies," Australasian Journal of Educational Technology, vol. 26, no. 4, pp. 477-493, 2010.

[22] M. Lakkala and L. Ilomäki, "A case study of developing ICTsupported pedagogy through a collegial practice transfer process," Computers \& Education, vol. 90, pp. 1-12, 2015.

[23] KNORK, "Promoting knowledge work practices in education," http://knork.info/website/.

[24] FNBE, The basics of the curriculum for upper secondary school, Opetushallitus, Helsinki, Finland, 2015.

[25] S. Paavola and K. Hakkarainen, "Trialogical approach for knowledge creation," in Knowledge Creation in Education, S. Tan, H. So, and J. Yeo, Eds., pp. 53-73, Springer, Singapore, 2014. 
[26] S. Paavola, M. Lakkala, H. Muukkonen, K. Kosonen, and K. Karlgren, "The roles and uses of design principles for developing the trialogical approach on learning," Research in Learning Technology, vol. 19, no. 3, pp. 233-246, 2011.

[27] Yin, Case Study Research. Design and Methods, Sage Publications, 5th edition, 2014.

[28] P. Atkinson and P. Hammersley, "Ethnography and participant observation," in Handbook of Qualitative Research, K. Denzin and Y. S. Lincoln, Eds., pp. 248-260, Sage Publication, 1994.

[29] C. Pole and M. Morrison, Ethnography for Education, Open University Press.

[30] H. Muukkonen, M. Lakkala, A. Toom, and L. Ilomäki, "Assessment of competences in knowledge work and object-bound collaboration during higher education courses," in Higher Education Transitions: Theory and Research, E. Kyndt, V. Donche, K. Trigwell, and S. Lindblom-Ylänne, Eds., EARLI book series New Perspectives on Learning and Instruction, pp. 288-305, 2017.

[31] C. Teddle and A. Tashakkori, "Major issues and controversies in the use of mixed methods in the social and behavioral studies," in Handbook of Mixed Methods in Social and Behavioral Research, A. Tashakkori and C. Teddle, Eds., pp. 3-50, Sage Publications, Thousand Oaks, Calif, USA, 2003.

[32] I. Newman, C. S. Ridenouer, C. Newman, and G. DeMarco M Jr., "A typology of research purposes and its relationship to mixed methods," in Handbook of Mixed Methods in Social and Behavioral Research, A. Tashakkori and C. Teddle, Eds., pp. 167188, Sage Publications, Thousand Oaks, Calif, USA, 2003.

[33] T. Francis, G. Østergaard, and S. Morse, "Phenomenon-based learning in agroecology: a prerequisite for transdisciplinarity and responsible action," Agroecology and Sustainable Food Systems, vol. 37, no. 1, pp. 60-75, 2013.

[34] W. Schenke, J. van Driel, F. Geijsel, H. Slighte, and M. Volman, "Characterizing cross-professional collaboration in research and development projects in secondary education," Teachers and Teaching: Theory and Practice, vol. 22, no. 5, pp. 553-569, 2016.

[35] S. Timmermans and I. Tavory, "Theory construction in qualitative research: from grounded theory to abductive analysis," Sociological Theory, vol. 30, no. 3, pp. 167-186, 2012.

[36] C. E. Coburn, "Collective sensemaking about reading: how teachers mediate reading policy in their professional communities," Educational Evaluation and Policy Analysis, vol. 23, no. 2, pp. 145-170, 2001.

[37] M. Lakkala, A. Toom, L. Ilomäki, and H. Muukkonen, "Redesigning university courses to support collaborative knowledge creation practices," Australian Journal of Educational Technology, vol. 31, pp. 521-536, 2015.

[38] M. Morris, J. Chrispeels, and P. Burke, “The power of two: linking external with internal teachers' professional development," Phi Delta Kappan, vol. 84, no. 10, pp. 764-767, 2003. 


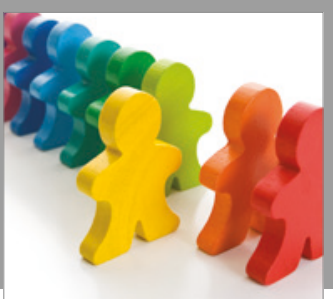

Autism

Research and Treatment
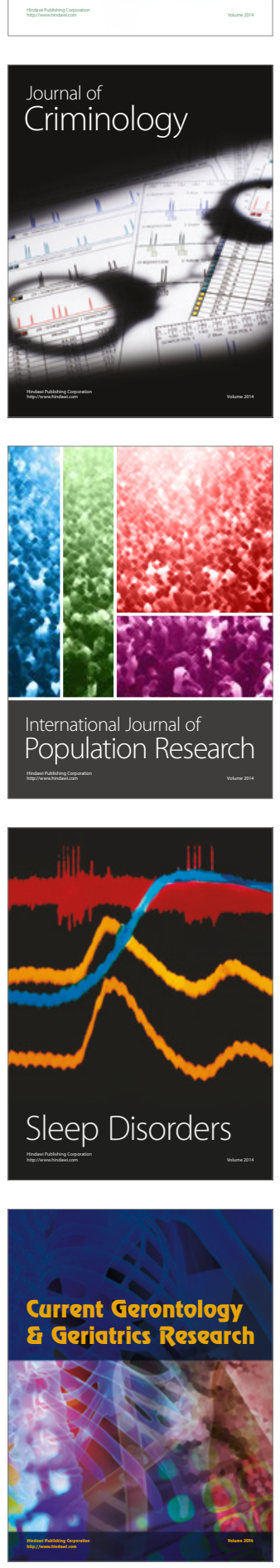

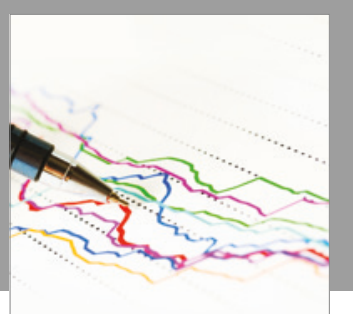

Economics

Research International

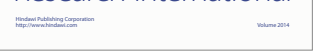

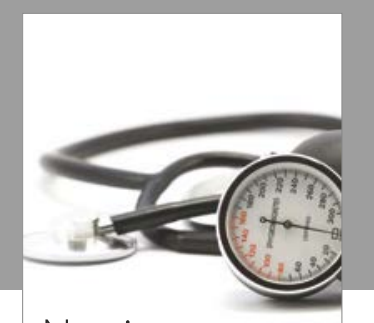

Nursing

Research and Practice

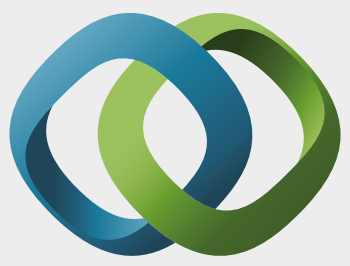

\section{Hindawi}

Submit your manuscripts at

https://www.hindawi.com
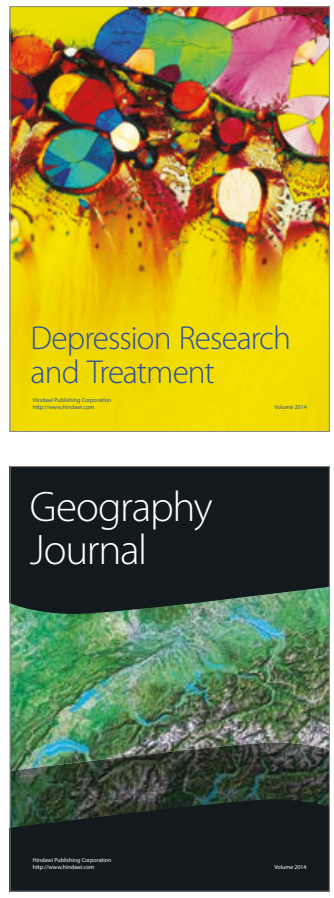
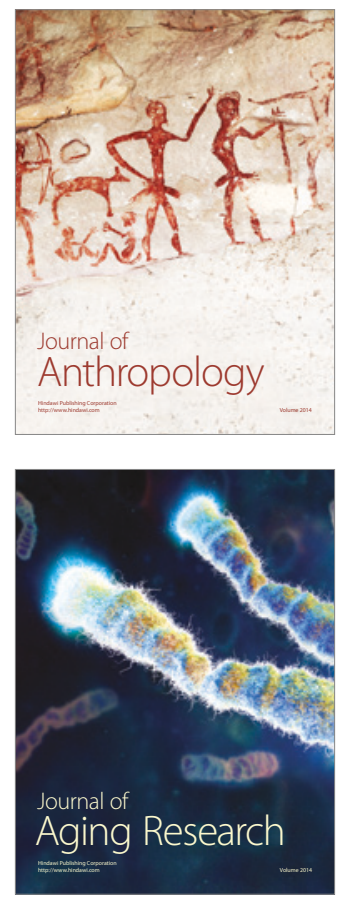
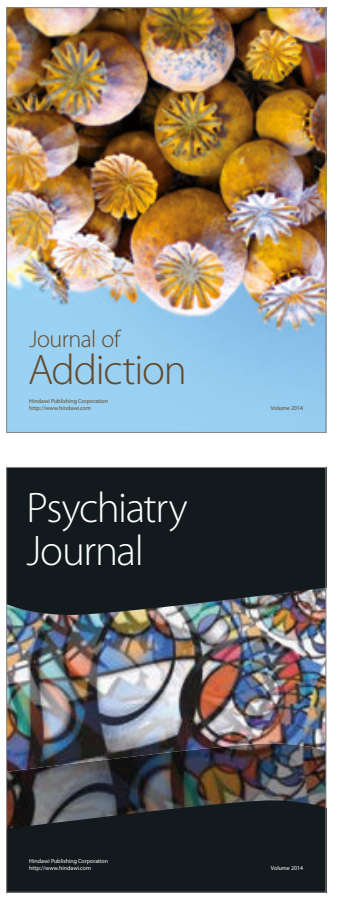

Child Development

Research

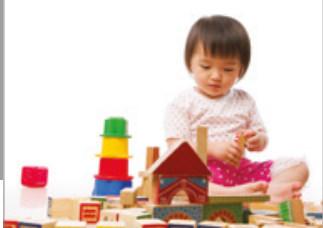

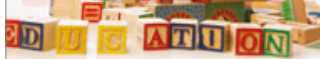
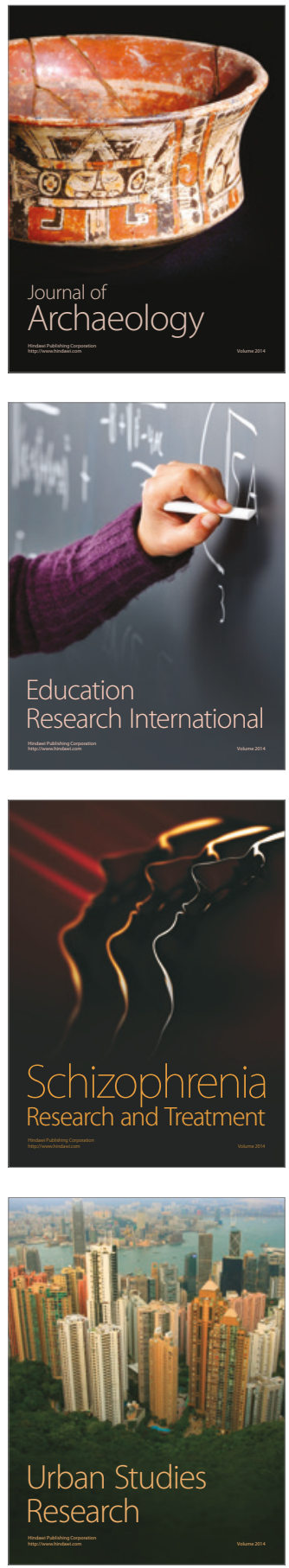